\title{
Organization of the Claustrum-to-Entorhinal Cortical Connection in Mice
}

\author{
Takuma Kitanishi and @Naoki Matsuo \\ Graduate School of Medicine, Osaka University, Osaka 565-0871, Japan, and Career-Path Promotion Unit for Young Life Scientists, Kyoto University, Kyoto \\ 606-8501, Japan
}

The claustrum, a subcortical structure situated between the insular cortex and striatum, is reciprocally connected with almost all neocortical regions. Based on this connectivity, the claustrum has been postulated to integrate multisensory information and, in turn, coordinate widespread cortical activity. Although studies have identified how sensory information is mapped onto the claustrum, the function of individual topographically arranged claustro- cortical pathways has been little explored. Here, we investigated the organization and function of identified claustro-cortical pathways in mice using multiple anatomical and optogenetic techniques. Retrograde and anterograde tracing demonstrated that the density of anterior claustrum-to-cortical projection differs substantially depending on the target cortical areas. One of the major targets was the medial entorhinal cortex (MEC) and the MEC-projecting claustral neurons were largely segregated from the neurons projecting to primary cortices M1, S1, or V1. Exposure to a novel environment induced c-Fos expression in a substantial number of MEC-projecting claustral neurons and some M1/S1/V1-projecting claustral neurons. Optogenetic silencing of the MEC-projecting claustral neurons during contextual fear conditioning impaired later memory retrieval without affecting basal locomotor activity or anxiety-related behavior. These results suggest that the dense, anterior claustro-MEC pathway that is largely separated from other claustro-cortical pathways is activated by novel context and modulates the MEC function in contextual memory.

Key words: claustrum; contextual fear memory; medial entorhinal cortex; optogenetics; sensory cortex

\section{Significance Statement}

The claustrum is a poorly understood subcortical structure reciprocally connected with widespread neocortical regions. We investigated the organization and function of identified claustro- cortical projections in mice using pathway-specific approaches. Anatomical tracing showed that the density of anterior claustrum-to-cortical projection is dependent on the target cortical areas and that the medial entorhinal cortex (MEC) is one of the major projection targets. Novel context exposure activated multiple claustro-cortical pathways and a large fraction of the activated neurons projected to the MEC. Optogenetic silencing of the claustro-MEC pathway during contextual fear learning suppressed subsequent memory retrieval. These results suggest that the dense claustro-MEC pathway is activated by novel context and modulates MEC function in contextual memory.

\section{Introduction}

The claustrum, a thin sheet-like mammalian brain structure located between neocortex and striatum, has topographic connections with the neocortex (Edelstein and Denaro, 2004). Part of the claustrum connects preferentially, but not exclusively, with

\footnotetext{
Received April 26, 2016; revised 0ct. 5, 2016; accepted 0ct. 6, 2016.

Author contributions: T.K. and N.M. designed research; T.K. performed research; T.K. and N.M. analyzed data; T.K. and N.M. wrote the paper.

This work was supported by the Japan Society for the Promotion of Science (Grant-in-Aid for JSPS Fellows $13 J 01624$ to T.K.) and the Ministry of Education, Culture, Sports, Science \& Technology in Japan (Grants-in-Aid for Scientific Research on Innovative Areas Memory Dynamism to N.M.).

The authors declare no competing financial interests.

Correspondence should be addressed to Naoki Matsuo, Department of Molecular and Behavioral Neuroscience, Graduate School of Medicine, Osaka University, 2-2 Yamadaoka, Suita, Osaka 565-0871, Japan. E-mail: n-matsuo@mbn.med.osaka-u.ac.jp.

DOI:10.1523/JNEUROSCI.1360-16.2016

Copyright (C) 2017 the authors $\quad 0270-6474 / 17 / 370269-12 \$ 15.00 / 0$
}

restricted areas of the neocortex. The entire claustrum is connected reciprocally through this coarse topographic arrangement with almost all areas of the neocortex (Smythies et al., 2013). Primarily based on this connectivity, the claustrum has been postulated to integrate multiple sensory information and, in turn, coordinate widespread cortical activity (Edelstein and Denaro, 2004; Crick and Koch, 2005). This integrative function of the claustrum has been thought to support the binding of information to create conscious percepts (Crick and Koch, 2005; Koubeissi et al., 2014; Chau et al., 2015). Neuronal activity in the claustrum in response to sensory stimuli has been investigated intensively in in vivo electrophysiological studies. Different sensory inputs, including visual, auditory, and somatosensory stimuli, activate particular parts of the claustrum, which presumably reflects the topographic cortico-claustral projection (Segundo and Machne, 1956; Spector et al., 1974; Olson and Graybiel, 1980; 
Sherk and LeVay, 1981; Clarey and Irvine, 1986; Remedios et al., 2010).

These anatomical and electrophysiological findings have revealed how multimodal sensory inputs are mapped onto the claustrum. However, how the information that is collected in the claustrum is transmitted back to individual cortical areas is poorly understood. For instance, it is unknown which claustrocortical pathways targeting distinct cortical areas are activated by a particular behavior and what the behavioral roles of the activated claustro-cortical pathways are. The lack of such pathwayspecific data is in part due to the structure of the claustrum. Because the topographic arrangement of the claustrum is coarse, cells projecting to distinct cortical areas are intermingled at each location of the claustrum (Norita, 1983; Minciacchi et al., 1985; Sloniewski et al., 1986; Majak et al., 2000). Therefore, accessing claustral neurons projecting to a specific cortical area selectively has been difficult with conventional pharmacological and electrophysiological approaches.

Here, we investigated the function of identified claustro-cortical projections in mice by using multiple pathway-specific approaches. Because the claustral projections in mice have been rarely explored (but see Zingg et al., 2014; Wang et al., 2016), we first examined the patterns of claustro-cortical projections using retrograde and anterograde tracers. Through this step, we found that a population of neurons in the anterior claustrum projects extensively to the medial entorhinal cortex (MEC). The MEC plays a key role in spatial and contextual information processing by serving as an interface between the hippocampus and neocortical regions (Maren and Fanselow, 1997; Lavenex and Amaral, 2000; Hafting et al., 2005; Steffenach et al., 2005; Jankowski and O'Mara, 2015). We further demonstrated that the claustro-MEC pathway was activated by novel context exposure and that silencing this pathway selectively during contextual fear conditioning suppresses later memory retrieval without affecting basal locomotor activity or anxiety-related behavior. These results suggest that the claustro-MEC pathway modulates MEC function in contextual memory without affecting broad cortical activity.

\section{Materials and Methods}

Plasmids. The pAAV-EF1 $\alpha$-enhanced green fluorescent protein (EGFP), pAAV-RC and pHelper (AAV Helper-Free System; Stratagene) plasmids were gifts from Ayumu Tashiro (Kitanishi et al., 2015). The following plasmids were obtained from Addgene: pAAV-pgk-Cre (No. 24593), pAAV-Syn-ChR(E90R-D156N-T159C)-2A-tDimer (No. 52494), pAAVEF1 $\alpha$-DIO-enhanced yellow fluorescent protein (EYFP) (No. 20296), pAAV-EF1 $\alpha$-DIO-hChR2(C128S/D156A or stable step-function opsin [SSFO])-EYFP (No. 35503), and pAAV-EF1 $\alpha$-DIO-hChR2(H134R)-EYFP (No. 20298). The pXR1 plasmid was obtained through the National Gene Vector Biorepository (Rabinowitz et al., 2002). The pAAV2/6 plasmid was obtained from the Penn Vector Core. The pAAV-EF1 $\alpha$-DIO-slow chlorideconducting channelrhodopsin (ChloC)-2A-EYFP plasmid was constructed by replacing a tDimer sequence in the pAAV-Syn-ChR(E90R-D156NT159C)-2A-tDimer plasmid with an EYFP sequence in frame and by inserting the resulting ChR(E90R-D156N-T159C)-2A-EYFP sequence into a pAAV-EF1 $\alpha$-DIO cassette in an inverted orientation.

Adeno-associated virus (AAV). AAV vectors were prepared as described previously with minor modifications (Kitanishi et al., 2015). AAVs with chimeric serotype $1 / 2$ were produced by cotransfecting four plasmids into HEK293T cells seeded on five $15 \mathrm{~cm}$ tissue culture dishes using a polyethylenimine transfection method. The transfected plasmids were pXR1 (10 $\mu \mathrm{g} / \mathrm{dish})$, pAAV-RC (10 $\mu \mathrm{g} / \mathrm{dish})$, pHelper (20 $\mu \mathrm{g} / \mathrm{dish})$, and the AAV plasmid containing the transgene of interest (20 $\mu \mathrm{g} / \mathrm{dish})$. AAV6-Cre was produced by cotransfecting three plasmids (pAAV2/6, pHelper, and pAAV-pgk-Cre) either into $1015 \mathrm{~cm}$ dishes of HEK293T cells at $20 \mu \mathrm{g} /$ dish using a polyethylenimine-transfection method or into five $15 \mathrm{~cm}$ dishes of AAV293 cells (Stratagene) at $22.5 \mu \mathrm{g} /$ dish using a calcium phosphate precipitation method. Forty-eight to 72 hours after transfection, cells were scraped off the dishes, pelleted, resuspended in $150 \mathrm{~mm} \mathrm{NaCl} / 20 \mathrm{~mm}$ Tris-HCl buffer, $\mathrm{pH}$ 8.0, and subjected to two cycles of freeze and thaw. The solution was incubated at $37^{\circ} \mathrm{C}$ for $30 \mathrm{~min}$ with 50 unit/ml benzonase nuclease (Millipore) and centrifuged at $3000 \times g$ for $15 \mathrm{~min}$ to remove cell debris. The supernatant was further incubated at $37^{\circ} \mathrm{C}$ for $30 \mathrm{~min}$ with $0.5 \%$ sodium deoxycholate (Sigma-Aldrich) and centrifuged at $3000 \times g$ for $15 \mathrm{~min}$. The supernatant was filtered through a sterile $0.45 \mu \mathrm{m}$ filter before being loaded into a heparin column (HiTrap; GE Healthcare). The column was washed with a $100 \mathrm{~mm} \mathrm{NaCl} / 20$ mm Tris- $\mathrm{HCl}, \mathrm{pH} 8.0$, solution. AAV was eluted with a series of $\mathrm{NaCl}$ solutions from 200 to $500 \mathrm{~mm}$ buffered with $20 \mathrm{~mm}$ Tris- $\mathrm{HCl}, \mathrm{pH}$ 8.0. The fractions from 300 to $500 \mathrm{~mm} \mathrm{NaCl}$ were collected and concentrated using an Amicon Ultra-4 centrifugal device (Millipore). The buffer was replaced with $\mathrm{PBS}$ containing $1 \mathrm{mM} \mathrm{MgCl}$, using the same centrifugal device. The final volume was $\sim 200 \mu \mathrm{l}$. The aliquots were stored at $-80^{\circ} \mathrm{C}$ until use. The genomic titers determined via qPCR were between $2.8 \times$ $10^{12}$ and $8.8 \times 10^{13}$ vector genomes $/ \mathrm{ml}$.

Surgery. All procedures on animals were approved and performed in accordance with the guidelines of Kyoto University and Osaka University. Stereotaxic surgeries were performed on male C57BL/6J mice at 11-18 weeks of age under anesthesia. The skull was exposed and small craniotomies were made dorsal to the injection sites. All injections were performed using a Hamilton syringe (33 gauge) at a speed of $300 \mathrm{nl} / \mathrm{min}$. For retrograde tracing $400 \mathrm{nl} /$ site of $0.5 \%$ cholera toxin B subunit (CTB) conjugated with Alexa Fluor 488 (CTB488; Invitrogen) and/or 0.5\% CTB conjugated with Alexa Fluor 594 (CTB594; Invitrogen) was injected to the following cortical areas: dorsal part of the medial entorhinal cortex (MEC; AP \pm 0.0, ML 3.1, DV 2.0), binocular area of the primary visual cortex (V1; AP - 4.0, ML 2.5, DV 0.7), barrel field of the primary somatosensory cortex (S1; AP -1.5, ML 2.5, DV 0.9), primary motor cortex (M1; AP +1.4, ML 1.4, DV 0.9), or prelimbic/infralimbic areas of the medial prefrontal cortex (mPFC; AP + 1.8, ML 0.30-0.35, DV 2.1). AP, $\mathrm{ML}$, and DV indicate the distance of injection sites (in millimeters) in the anteroposterior direction from the lambdoid suture (for the MEC) or from the bregma (for the other areas), that in the mediolateral direction from the midline, and that in the dorsoventral direction from the cortical surface, respectively. In six of the 18 mice used, CTB488 was injected unilaterally and retrograde labeling was measured in the ipsilateral claustrum. In the remaining mice, because claustro-cortical projection in mice is predominantly unilateral (Zingg et al., 2014), CTB488 and CTB594 were injected bilaterally and the labeling was measured in both hemispheres of the claustrum. The CTB-injected mice were subjected to environmental exposure $7 \mathrm{~d}$ after surgery (see "Behavioral procedures"). For anterograde tracing, $400 \mathrm{nl} /$ site of AAV1/2-EF1 $\alpha$-EGFP aimed at the claustrum (AP +1.5, ML 2.5, DV 2.8; AP \pm 0.0 , ML 3.6, DV 3.2) was injected and the mice were killed $14 \mathrm{~d}$ after surgery (see "Histology"). For optogenetic experiments, $400 \mathrm{nl} /$ site of the AAV6-Cre vector was injected bilaterally to the dorsal MEC (AP \pm 0.0, ML 3.1, DV 2.0) and the AAV1/ 2-EF1 $\alpha$-DIO-slow ChloC-2A-EYFP, AAV1/2-EF1 $\alpha$-DIO-SSFO-EYFP, or control AAV1/2-EF1 $\alpha$-DIO-EYFP vector aimed at the lateral claustrum $(600 \mathrm{nl} /$ site; AP +1.0, ML 3.0, DV 2.5). Plastic optical fibers (Ø250 $\mu \mathrm{m}$; CK-10; Mitsubishi rayon) were also implanted bilaterally terminating dorsal to the claustrum (AP + 1.0, ML 3.0, DV 2.0). Behavioral experiments with these mice started $23 \pm 2 \mathrm{~d}$ after surgery. Some of the control mice injected with the AAV1/2-EF1 $\alpha$-DIO-EYFP vector were also used for tracing experiments (see Fig. $4 D-H$ ). All mice were housed individually after surgery.

Behavioral procedures. All behavioral experiments were performed during the light period of the light/dark cycle. To investigate c-Fos protein expression after novel context exposure, naive C57BL/6J male mice were placed in a rectangular chamber $(33 \times 25 \mathrm{~cm}$; depth, $40 \mathrm{~cm}$; 150 lux $)$ novel to the mice for 6 min only once (novel group) or 10 times daily (familiar group) (see Fig. 6). CTB-injected mice (see Fig. 7) were also exposed to the same chamber once for $6 \mathrm{~min}$. All mice were killed $90 \mathrm{~min}$ after the final environmental exposure.

For optogenetic experiments, animals were subjected sequentially to an open-field test, elevated plus maze test, and contextual fear condition- 
ing test. To activate slow ChloC (Wietek et al., 2014), $473 \mathrm{~nm}$ light pulses $(20 \mathrm{~ms}, 1 \mathrm{~Hz},>5 \mathrm{~mW}$ ) emitted from a DPSS laser (SDL-473-200T; Shanghai Dream Lasers Technology) were delivered through implanted optic fibers to the claustrum bilaterally in all behavioral tests. To activate and deactivate SSFO (Yizhar et al., 2011), a blue light pulse centered at $475 \mathrm{~nm}$ (>2 mW, RETRA 2-LCR-FA, Lumencor) for $5 \mathrm{~s}$ and a yellow light pulse centered at $575 \mathrm{~nm}(>2 \mathrm{~mW}$, RETRA 2-LCR-FA) for $10 \mathrm{~s}$ were administered bilaterally in all behavioral tests, respectively.

The open -field test was performed in a square chamber $(50 \times 50 \mathrm{~cm}$; depth, $40 \mathrm{~cm} ; 150$ lux) with a white plastic floor and white side walls, with an A4-sized black cue card on one of the walls. Mice were placed individually at the center of the chamber. For experiments using slow ChloC, mice were allowed to explore for $9 \mathrm{~min}$ in total. Blue light pulses were delivered to the claustrum between 3 and $6 \mathrm{~min}$. For experiments with SSFO, mice were allowed to explore the chamber for 2 consecutive 6 min sessions. A blue light pulse was delivered immediately before the first session and a yellow light pulse was given between the first and the second sessions. Animal position was tracked at a rate of $50 \mathrm{~Hz}$ with an overhead camera (Axona). Locomotor activity was calculated offline as distance traveled per minute (MATLAB; The MathWorks).

The elevated plus maze consisted of two open arms $(25 \times 5 \mathrm{~cm}$, gray), two closed arms $(25 \times 5 \mathrm{~cm}$, gray) with transparent walls (height, $15 \mathrm{~cm})$, and a central platform $(5 \times 5 \mathrm{~cm}$, gray) that connected the four arms. The maze was placed $50 \mathrm{~cm}$ above the floor. Mice were placed individually on the central platform and allowed to explore the maze freely. For experiments using slow ChloC, blue light pulses were delivered between 3 and $6 \mathrm{~min}$ within the total session of $9 \mathrm{~min}$. For experiments with SSFO, mice were allowed to explore the maze for 2 consecutive 6 min sessions. A blue light pulse was delivered immediately before the first session and a yellow light pulse was given between the first and the second session. Video images were obtained at a rate of $2 \mathrm{~Hz}$ with an overhead camera (O'Hara). Animal positions were determined offline with MATLAB and then the proportion of open arm entries was calculated as the number of open arm entries divided by the number of total arm entries.

Contextual fear conditioning was conducted in a rectangular chamber $(33 \times 25 \mathrm{~cm}$; depth, $40 \mathrm{~cm}, 150 \mathrm{lux})$ with white plastic side walls and a stainless-steel grid floor (O'Hara) (Matsuo, 2015). Mice were placed individually in the chamber for $360 \mathrm{~s}$. Electrical foot shocks $(0.4 \mathrm{~mA}, 2 \mathrm{~s})$ were presented 3 times starting at 180,240, and 300 s. For the slow ChloC experiments, blue light pulses were given throughout the conditioning session. For the SSFO experiments, a blue light pulse was given immediately before placing the mouse into the chamber and a yellow light pulse was given after taking the mouse out from the chamber. One and/or 24 hours later, mice were placed into the same chamber for $180 \mathrm{~s}$ without foot shocks or light irradiation to evaluate their contextual fear memory. Video images were captured at a rate of $2 \mathrm{~Hz}$ with an overhead camera and the proportion of freezing was automatically scored with a bin length of $30 \mathrm{~s}$ using TimeFZ4 software (O'Hara).

Histology. Mice were transcardially perfused with saline and then $4 \%$ paraformaldehyde/0.1 m phosphate buffer while under anesthesia. Brains were removed and kept in the same fixative overnight at $4^{\circ} \mathrm{C}$. Sagittal (for all figures but Fig. 4C,F) or horizontal (see Fig. 4C,F) sections were prepared at a thickness of $40 \mu \mathrm{m}$ using a vibratome (VT1200S; Leica). For immunohistochemistry, the sections were incubated sequentially in $0.3 \%$ Triton-X 100 in 5\% BSA/PBS for $30 \mathrm{~min}$ at room temperature, primary antibodies diluted in $5 \% \mathrm{BSA} / \mathrm{PBS}$ overnight at $4^{\circ} \mathrm{C}$, and then the corresponding goat-derived secondary antibodies conjugated with Alexa Fluor dye (Invitrogen) diluted in $5 \%$ BSA/PBS overnight at $4^{\circ} \mathrm{C}$. After each incubation, sections were washed with PBS. Some sections were counterstained with $0.5 \mu \mathrm{g} / \mathrm{ml}$ 4,6-diamidino-2-phenylindole (DAPI; Invitrogen). The primary antibodies used were as follows: chicken antibody to GFP (1:2000, ab13970; Abcam, RRID:AB_300798), rabbit antibody to c-Fos (1:1000, sc-52; Santa Cruz Biotechnology, RRID:AB_2106783; 1:2000, Ab-5; Calbiochem, RRID:AB_213663), mouse antibody to latexin (1:150, PC3.1, gift from Yumiko Hatanaka, RRID:AB_2571634) (Arimatsu et al., 1992), mouse antibody to NeuN (1:2000, MAB377; Millipore, RRID:AB_2298772), mouse antibody to CaMKII $\alpha$ subunit (1:1000, 05-532; Millipore, RRID:AB_309787), mouse antibody to GAD67 (1:1000, MAB5406; Millipore, RRID:AB_2278725), rabbit antibody to VGLUT1 (1:1000, 135-303; Synaptic Systems, RRID: AB_887876), and rat antibody to Ctip2 (1:1000, ab18465; Abcam, RRID: AB_2064130). Fluorescent images were obtained with an Axioplan 2 imaging microscope (Zeiss) with a $10 \times$ objective [numerical aperture (NA) 0.45] (see Fig. 4G,H) and a TCS SP8 confocal microscope (Leica) equipped with $20 \times$ (NA 0.75) and $63 \times$ (NA 1.20) objectives (for the details of the imaging of all of other images, see next paragraph).

Cell counting. The claustrum was identified as a latexin-positive region with densely packed large to medium-sized neurons that were situated posteromedial to the insular cortex, anterolateral to the striatum, and dorsal to the rhinal fissure (see Fig. 1) (Smythies et al., 2013). Note that this region is also called the insular claustrum and is distinct from the endopiriform nucleus or piriform claustrum that is ventral to the rhinal fissure. Claustral cells that were positive for CTB, c-Fos, CaMKII $\alpha$, GAD67, NeuN, or DAPI were counted on sagittal sections from 3 mediolateral levels of the claustrum referred to as the medial $(\sim 1.5 \mathrm{~mm}$ from the midline $)$, intermediate $(\sim 2.3$ $\mathrm{mm}$ from the midline), and lateral ( $\sim 3.0 \mathrm{~mm}$ from the midline) claustrum. This range (i.e., $1.5-3.0 \mathrm{~mm}$ lateral to the midline) contains the anterior half of the claustrum along the anteroposterior axis. The posterior half of the claustrum, the anteroposterior axis of which runs almost parallel to the sagittal plane, was excluded from the analyses for technical reasons. At each mediolateral level, three (for CTB and c-Fos) or two (for CaMKII $\alpha$ and GAD67) adjacent sagittal sections per mouse were selected before imaging the claustrum under a microscope. From each selected section, an optically sectioned image that included the claustrum was acquired with a TCS SP8 confocal microscope. Within each image, the claustrum was equally divided into dorsal, central, and ventral parts and all of the labeled claustral cells in each part were counted. The counting of markers that were localized in nuclei (c-Fos, NeuN, and DAPI) was performed with an automated software program that detects nuclei (Image-based Tool for Counting Nuclei; Byun et al., 2006). The other markers (CTB, CaMKII $\alpha$, and GAD67) were counted manually. The manual cell counts of CTB were highly correlated between the experimenter and a second counter $(r=0.97, p<0.001$, Pearson correlation). For CTB and c-Fos, the cells counts from the same mediolateral and dorsoventral parts were summed and normalized by the number of neurons in the same claustrum part to determine the percentage of marker-positive (i.e., $\mathrm{CTB}^{+}$or $\mathrm{c}-\mathrm{Fos}^{+}$) claustral neurons. Stereological methods were not used because of this normalization. The cell counts from all parts of the claustrum were pooled for the analyses in Figures 3 and 7. Neurons positive for c-Fos were also counted using sagittal sections in the following areas: the entire dorsoventral part of the MEC ( $\sim 3.0 \mathrm{~mm}$ from the midline), $\mathrm{V} 1(\sim 2.3$ $\mathrm{mm}$ from the midline), $\mathrm{S} 1$ ( $\sim 2.3 \mathrm{~mm}$ from the midline $), \mathrm{M} 1(\sim 1.5 \mathrm{~mm}$ from the midline), and the hippocampal CA1/CA3 areas $(\sim 1.5 \mathrm{~mm}$ from the midline) (see Fig. $6 H$ ). The cell counting was performed in the pyramidal cell layer for CA1 and CA3 areas and was performed including all cortical layers 1-6 for the other areas.

Statistical analysis. Statistical analyses were performed using SPSS statistics software (IBM, RRID:SCR_002865). Data are shown as mean \pm SEM in figures and texts unless otherwise specified.

\section{Results}

\section{Organization of claustro-cortical projections}

We investigated the claustro-cortical projections by injecting the same amount of CTB488 into one of the following cortical areas: the dorsal part of the MEC, V1, S1, M1, or mPFC (Fig. 1A). The claustrum was identified by densely packed neurons that were situated posteromedial to the insular cortex and dorsal to the rhinal fissure (Fig. 1B; Smythies et al., 2013). The density of the $\mathrm{NeuN}$-positive cells was higher in the claustrum compared with the adjacent deep layers of the insular cortex (Fig. 1B; claustrum, $1712 \pm 25$ cells $/ \mathrm{mm}^{2}$; insular cortex, $1385 \pm 42$ cells $/ \mathrm{mm}^{2} ; t_{52}=$ $10.5, p<0.001$, two-tailed unpaired $t$ test). When CTB488 was injected into the dorsal MEC (Fig. $1 C$ ), many somata were labeled with CTB488 in the ipsilateral claustrum (Fig. 1D). The labeled somata were distributed within the oval-shaped area densely expressing latexin (Fig. 1D), which is highly expressed in the claustrum but only sparsely in the overlaying insular cortex (Ari- 
A
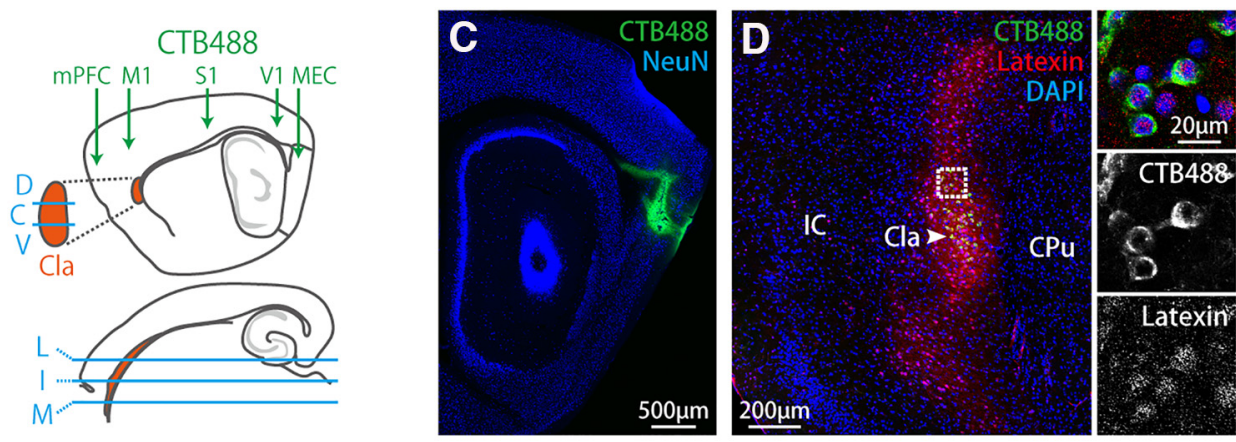

B
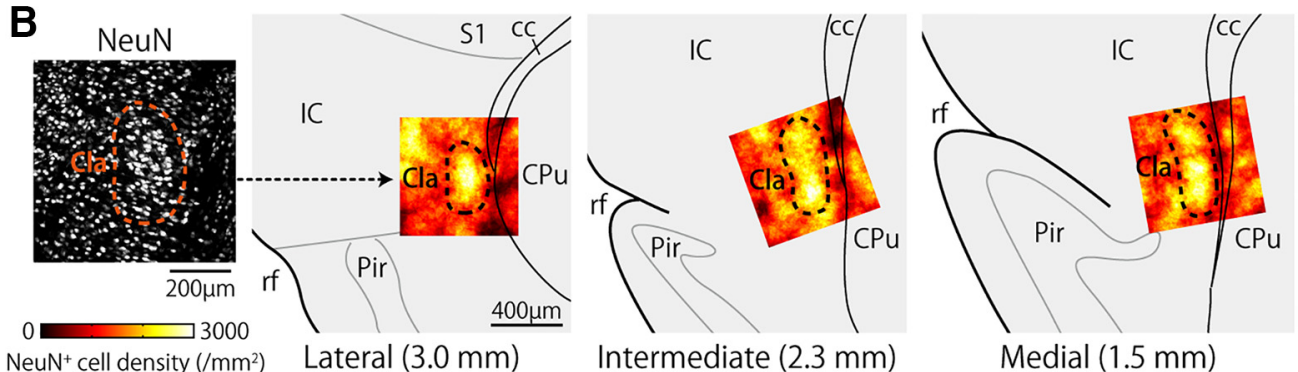

Medial $(1.5 \mathrm{~mm})$

Figure 1. Tracing claustro- cortical projections in mice. A, Schematic of retrograde tracing experiments. (TB488 was injected into one of the indicated cortical areas (top). Proportions of CTB488-labeled neurons were examined in the dorsoventral claustral segments (top) that were equally divided at each mediolateral level (bottom) in the ipsilateral hemisphere (bottom). D, C, V, $\mathrm{M}, \mathrm{I}$, and L indicate the dorsal, central, ventral, medial, intermediate, and lateral segments of the claustrum, respectively. $\boldsymbol{B}$, Identification of the claustrum. The photomicrograph on the far left is of a parasagittal section that shows densely packed $\mathrm{NeuN}^{+}$cells in the lateral claustrum. The three images on the right show the density maps of NeuN ${ }^{+}$cells in the lateral, intermediate, and lateral claustrum that are overlaid on a corresponding atlas. The numbers indicate the distance from the midline. The map of the lateral claustrum corresponds to the photomicrograph on the far left. $B, D$, $\mathrm{Cla}$, Claustrum; IC, insular cortex; (Pu, caudate putamen; S1, primary somatosensory cortex; Pir, Piriform cortex; cc, corpus callosum; rf, rhinal fissure. C, D, CTB488 was injected into the dorsal MEC. Parasagittal section shows the injection site of CTB488 ( $C$ and labeled somata in the claustrum that expressed latexin preferentially $(\boldsymbol{D})$. The area indicated by a dotted box in $\boldsymbol{D}$ is shown in the right panels.

matsu et al., 1992). Because the claustrum in mice has a slender structure extending in the anteromedial to posterolateral direction (Franklin and Paxinos, 2008), we examined CTB488 labeling at three mediolateral levels of the claustrum that covered the anterior half of the claustrum along the anteroposterior axis (Fig. $1 A, B)$. In addition, we equally divided the claustrum into three dorsoventral parts at each mediolateral level (Fig. 1A). For all cortical injection sites, CTB488-labeled somata were found in the claustrum (Fig. 2A,B). However, the distributions of the labeled neurons differed substantially depending on the corticalinjecting sites, mediolateral, and dorsoventral locations within the claustrum (Fig. $2 C ; p<0.001$, for all main effects: injection site $\times$ mediolateral and injection site $\times$ dorsoventral interactions, three-way ANOVA). Among these three factors, we first examined the mediolateral and dorsoventral distributions of the CTB488-labeled neurons for each injection site. Along the mediolateral axis, the proportion of CTB488-labeled neurons was higher in the lateral claustrum than in the medial claustrum when CTB488 was injected into the MEC, mPFC, or V1 (Fig. 2D; $p<$ 0.001 , post hoc Bonferroni test after two-way repeated-measures ANOVA). Conversely, the proportion was higher in the medial claustrum than in the lateral claustrum when injected into M1 (Fig. 2D; $p<0.001$, post hoc Bonferroni test). When injected into $\mathrm{S} 1$, the proportion did not differ significantly along the mediolateral axis (Fig. $2 D ; p>0.1$, post hoc Bonferroni test). Along the dorsoventral axis, the proportion of CTB488-labeled neurons was highest in the central part of the claustrum when CTB488 was injected into either MEC or V1 (Fig. $2 E$; $p<0.05$, post hoc Bonferroni test after two-way repeated-measures ANOVA). When injected into $\mathrm{M} 1$, the proportion was higher in the dorsal part than the ventral part of claustrum (Fig. $2 E ; p<0.01$, post hoc
Bonferroni test). The proportion did not differ significantly along the dorsoventral axis when injected into either S1 or the mPFC (Fig. 2E; $p>0.05$, post hoc Bonferroni test). These observations indicate that claustro-cortical projections in mice are organized topographically along both the mediolateral and dorsoventral axes of the anterior claustrum.

We next examined the differences in the proportions of the CTB488-labeled neurons among the injection sites at each claustrum location. In the lateral and intermediate claustrum, neurons projecting to the MEC or MPFC were more abundant than those projecting to primary cortices: V1, S1, or M1 (Fig. 2D; $p<0.05$, post hoc Bonferroni test after two-way repeatedmeasures ANOVA). Particularly in the lateral claustrum, the proportion of MEC-projecting neurons was 3.3-12.8 times greater than that of neurons projecting to primary cortices. In the medial claustrum, neurons projecting to the MEC or M1 were more abundant than those projecting to $\mathrm{S} 1$ or $\mathrm{V} 1$ ( $p<0.05$, post hoc Bonferroni test), whereas the proportion of neurons projecting to the mPFC did not differ significantly from that of neurons projecting to any other areas ( $p>0.05$, post hoc Bonferroni test). For the dorsoventral axis, there was a difference: in the ventral part of claustrum, the neurons projecting to the MEC or mPFC were more abundant $(p<0.01$, post hoc Bonferroni test after two-way repeated-measures ANOVA) than those projecting to primary cortices (V1, S1, and M1). In the dorsal part of claustrum, MEC-projecting and $\mathrm{mPFC}$-projecting neurons were more abundant than V1-projecting neurons ( $p<0.05$, post hoc Bonferroni test). These results indicated that, among the cortical areas examined, the MEC was the largest projection target of the anterior claustrum, with the $\mathrm{MPFC}$ being the second largest. 

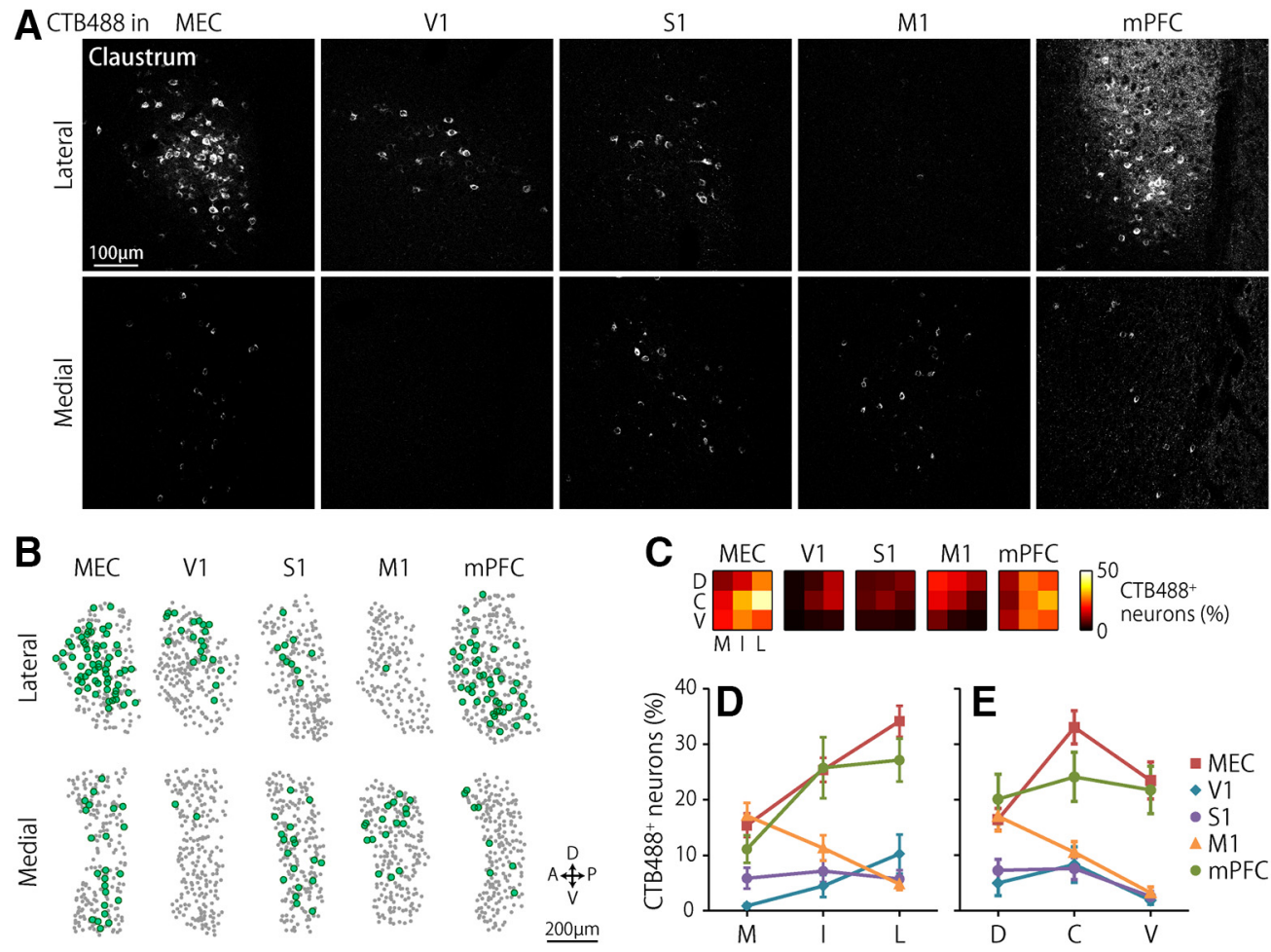

Figure 2. Distributions of cortically projecting claustral neurons. $A$, Representative CTB488 labeling in the lateral (top) and medial (bottom) claustrum. $\boldsymbol{A}-\boldsymbol{C}$, Labels above the images refer to the injection sites of (TB488. B, Representative distributions of (TB488-labeled neurons (green dots) in the lateral (top) and medial (bottom) claustrum. Gray dots indicate the claustral neurons that were positive for NeuN. D, V, A, and P indicate the dorsal, ventral, anterior, and posterior directions, respectively. C, Mean percentages of (TB488-labeled neurons in each segment of the claustrum. The columns and rows in each matrix correspond to the mediolateral and dorsoventral locations within the claustrum, respectively (e.g., the top left element in the matrix corresponds to the dorsomedial part of the claustrum). $C-E, M, I, L, D, C$, and V indicate the medial, intermediate, lateral, dorsal, central, and ventral segments of the claustrum, respectively. MEC: $n=10$ hemispheres, other cortical areas: $n=5$ hemispheres per area. $\boldsymbol{D}, \boldsymbol{E}$, Percentages of (TB488-labeled neurons in each mediolateral $(\boldsymbol{D})$ and dorsoventral $(\boldsymbol{E})$ segment of the claustrum. The cells along the dorsoventral $(\boldsymbol{D})$ and mediolateral $(\boldsymbol{E})$ axes were pooled in this analysis.

A

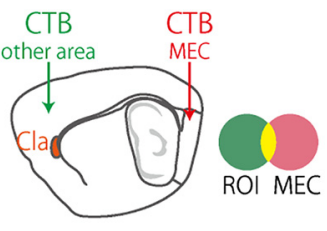

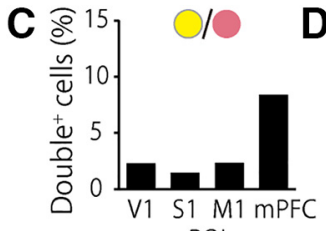

$\mathrm{ROI}$

CTB488
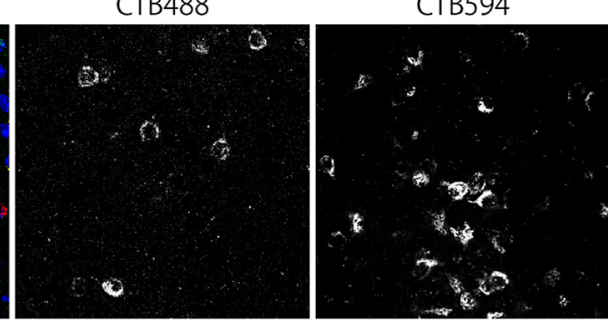

Figure 3. Target-specific segregation of claustral projection neurons. $A$, Schematic of experiments. Either CTB594 or CTB488 was injected into the MEC, whereas the other was injected into one of four cortical areas: $\mathrm{V} 1, \mathrm{S1}, \mathrm{M1}$, or $\mathrm{mPFC}$. $\boldsymbol{B}$, Representative confocal images of the claustrum of a mouse injected with CTB488 and CTB594 into M1 and the MEC, respectively. Note that CTB488 ${ }^{+}$and CTB594 ${ }^{+}$cells are largely segregated. C, D, Percentage of CTB488 and CTB594 double-positive cells within the claustral cells projecting to the MEC $(\boldsymbol{C})$ or the indicated cortical area $(\boldsymbol{D})$. Total number of cells counted was 8766 from 16 hemispheres.

Target-dependent segregation of claustro-cortical neurons The uneven distribution of claustro-cortical neurons and the larger number of MEC-projecting neurons suggest that the MEC-projecting neurons may form their own population segregated from neurons projecting to other cortical areas. To test this idea, we counted CTB488 and CTB594 double-labeled cells in the claustrum after CTB488 and CTB594 were injected into the dorsal MEC and one of the other four regions of interest (ROIs): V1, S1, M1, or the mPFC (Fig. $3 A, B)$. In all cases, CTB488-labeled and CTB594-labeled cells were intermingled within the claustrum. The proportion of double-positive cells within neurons projecting to either the MEC (Fig. 3C) or ROI (Fig. 3D) ranged from $2.3 \%$ to $8.0 \%$ when the ROI was one of the primary cortices (V1, S1, or M1). When the ROI was the mPFC, the proportion of double-positive cells was $8.4 \%$ (Fig. 3C) and $12.5 \%$ (Fig. $3 D$ ), significantly larger than the independent distributions $\left(p<0.01\right.$, residual analysis after $\chi^{2}$ test of independence). These results suggest that the claustral neurons projecting to the MEC are largely segregated from those projecting to other cortical areas, with modest overlap with mPFCprojecting neurons.

\section{Claustrum innervates the entire dorsoventral MEC}

To visualize the axons of claustral projection neurons, we injected AAV expressing EGFP under the control of the elongation factor 

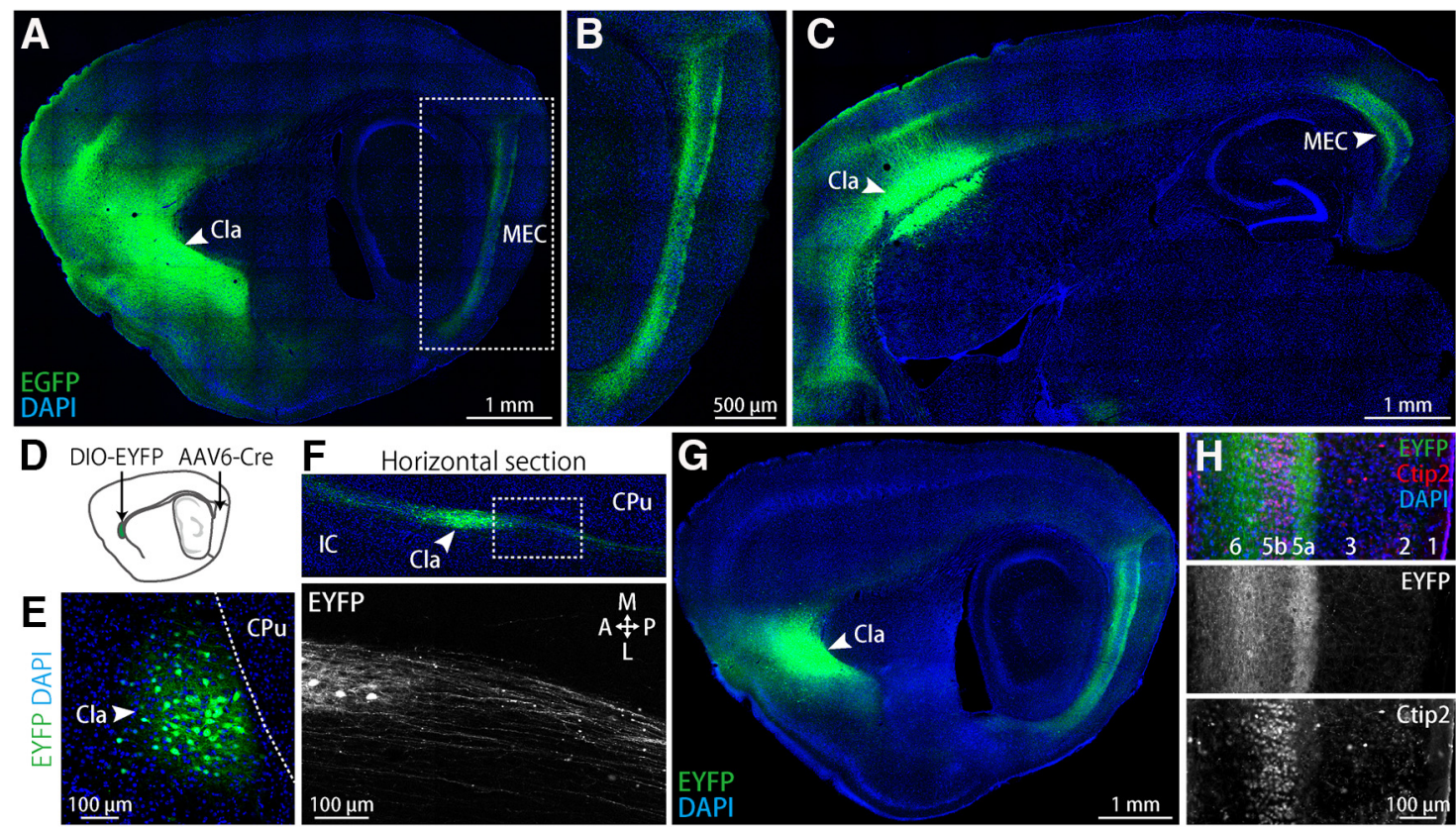

Figure 4. Claustrum projects to deep layers of MEC. $A-C, A A V 1 / 2-E F 1 \alpha$-EGFP was injected in the claustrum for anterograde tracing. Representative parasagittal section showing dense labeling in the deep layers of the MEC along the entire dorsoventral axis $(\boldsymbol{A})$. The area indicated by a dotted box is shown in $\boldsymbol{B}$. Representative horizontal section is shown in $\boldsymbol{C}$. Cla, Claustrum. $\boldsymbol{D}$, Schematic of the double infection approach to visualize MEC-projecting claustral neurons. AAV6-Cre and AAV1/2-EF1 $\alpha$-DI0-EYFP vectors were injected into the dorsal MEC and the lateral claustrum, respectively. $\boldsymbol{E}$, Representative sagittal image around the claustrum shows the restricted EYFP expression within the claustrum. Dotted line indicates the border between the claustrum and the caudate putamen (CPu). $\boldsymbol{F}$, Confocal image of a horizontal section showing claustral neurons that project to the MEC (top, green) extend their axons in a caudal direction (bottom). The area indicated by a white box in the top panel is shown in the bottom panel. IC, Insular cortex. A, P, M, and L represent the anterior, posterior, medial, and lateral directions, respectively. G, Representative parasagittal section showing dense EYFP labeling in the deep layers of the MEC. $\boldsymbol{H}$, Parasagittal image of the dorsal MEC stained for a layer $5 \mathrm{~b}$ marker, Ctip2.

$1 \alpha(\mathrm{EF} 1 \alpha)$ promoter (AAV1/2-EF1 $\alpha$-EGFP) as an anterograde tracer into the claustrum (Fig. $4 A-C, n=4$ hemispheres). Due to the small size of the claustrum, EGFP-labeled somata around the injection site were distributed in the claustrum and modestly in the adjacent cortex and striatum (Fig. $4 A, C$ ). The EGFP-labeled axons densely occupied the MEC and insular cortex, but were distributed sparsely in V1 and S1 and scarcely in the hippocampus (Fig. $4 A-C$ ). Within the MEC, the axons preferentially occupied the entire dorsoventral and mediolateral extent of the deep layers (Fig. $4 B, C$ ).

Although these EGFP-labeled axons in the MEC most likely originated from claustral neurons, they could have originated from nearby cortical/striatal neurons. We aimed to distinguish between these possibilities by specifically visualizing MEC-projecting claustral neurons without leakage to adjacent structures. To achieve this, we used an AAV double infection approach. In this approach, retrograde-infecting AAV expressing Cre recombinase (AAV6-Cre; Aronoff et al., 2010) were injected into the dorsal MEC and a Credependent reporter AAV that expresses EYFP after recombination (AAV1/2-EF1 $\alpha$-DIO-EYFP) was injected into the lateral claustrum (Fig. 4D). EYFP-expressing somata were distributed within the claustrum, but not in the nearby cortex or striatum (Fig. 4E). EYFPlabeled axons derived from these claustral neurons ran through the deep layers of the cortex in a caudal direction (Fig. $4 F$ ) and densely occupied the entire deep layers of the MEC (Fig. 4G). This dorsoventral labeling of axons after the AAV6-Cre injection only into the dorsal MEC suggests that single claustral neurons extend their axons to both the dorsal and ventral MEC. To visualize the layered structure of the MEC, we stained parasagittal sections for a marker of layer 5b, Ctip2 (Sürmeli et al., 2015). The EYFP-labeled axons were densely distributed in the more superficial (layer 5a) and deeper (layer 6) layers adjacent to the Ctip2-positive layer (Fig. 4H). The labeled axons were also moderately distributed in layer $5 \mathrm{~b}$ and sparsely in layers 2 and 3 (Fig. $4 H$ ).

We histochemically characterized the MEC-projecting claustral neurons. More than $99 \%$ of claustro-MEC neurons visualized by CTB488 injection into the dorsal MEC expressed the $\alpha$-subunit of calmodulin kinase II (CaMKII $\alpha$ ), but not the 67 $\mathrm{kDa}$ isoform of glutamate decarboxylase (GAD67; Fig. 5A,B). The axons labeled through the AAV double infection approach had axonal boutons colocalized with vesicular glutamate transporter 1 (VGLUT1) within the MEC (Fig. 5C). The dendrites of these MEC-projecting claustral neurons had dendritic spines (Fig. 5D). These results indicate that the MEC-projecting claustral neurons are spiny and form glutamatergic synapses in the MEC. These cells are likely to be type 1 spiny projection neurons in the claustrum (Brand, 1981; LeVay and Sherk, 1981).

\section{Exposure to novel environments activates the claustrum}

We investigated experience-dependent neuronal activation by staining for an immediate-early gene product, c-Fos (Morgan et al., 1987). Mice were briefly exposed to a novel chamber once (novel group) or to the same chamber 10 times daily (familiar group; Fig. 6A). The locomotor activity of the familiar group gradually decreased over the first $3 \mathrm{~d}\left(F_{(2,8)}=45.6, p<0.001\right.$, one-way repeated-measures ANOVA) and remained unchanged thereafter $\left(F_{(6,24)}=2.3, p>0.05\right.$, one-way repeated-measures ANOVA; Fig. $6 B$ ), indicating that the mice were fully familiarized to the chamber by day 10 . All mice were killed 90 min after the final exposure together with home-caged controls (home cage group). We observed robust c-Fos expression in the claustrum in the novel group (Fig. 6C). More than $98 \%$ of these c-Fos-positive cells were CaMKII $\alpha$ positive and GAD67 negative (Fig. $6 D, E$ ). The proportion of c-Fos-positive cells varied according to the 

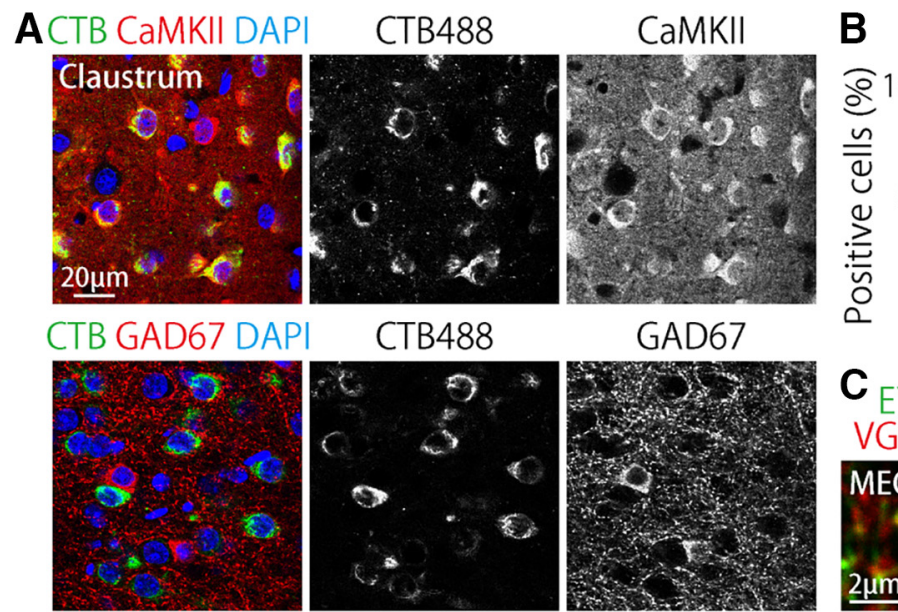

GAD67
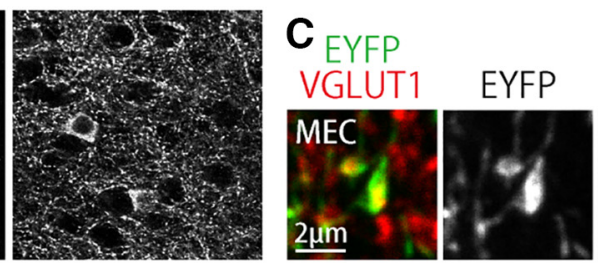

Figure 5. Characterization of MEC-projecting claustral neurons. $A$, Confocal images of the claustrum from mice injected with CTB488 into the dorsal MEC stained for CaMKIll $\alpha$ (top) or GAD67 (bottom). $\boldsymbol{B}$, Percentage of CaMKII $\alpha{ }^{+}$or GAD67 ${ }^{+}$cells within the CTB488 ${ }^{+}$claustral neurons. The number indicates the mean percentage of the GAD67 group. ${ }^{* *} p<0.01, t_{(8)}=352.1$, two-tailed unpaired $t$ test. $n=5$ mice. C, Single optical section in the MEC of a mouse subjected to the double infection approach showing axonal boutons co-localized with VGLUT1. D, Representative image of a dendrite of an MEC-projecting claustral neuron visualized with the double injection approach. Note that the dendrite has dendritic spines. Scale bar, $2 \mu \mathrm{m}$.
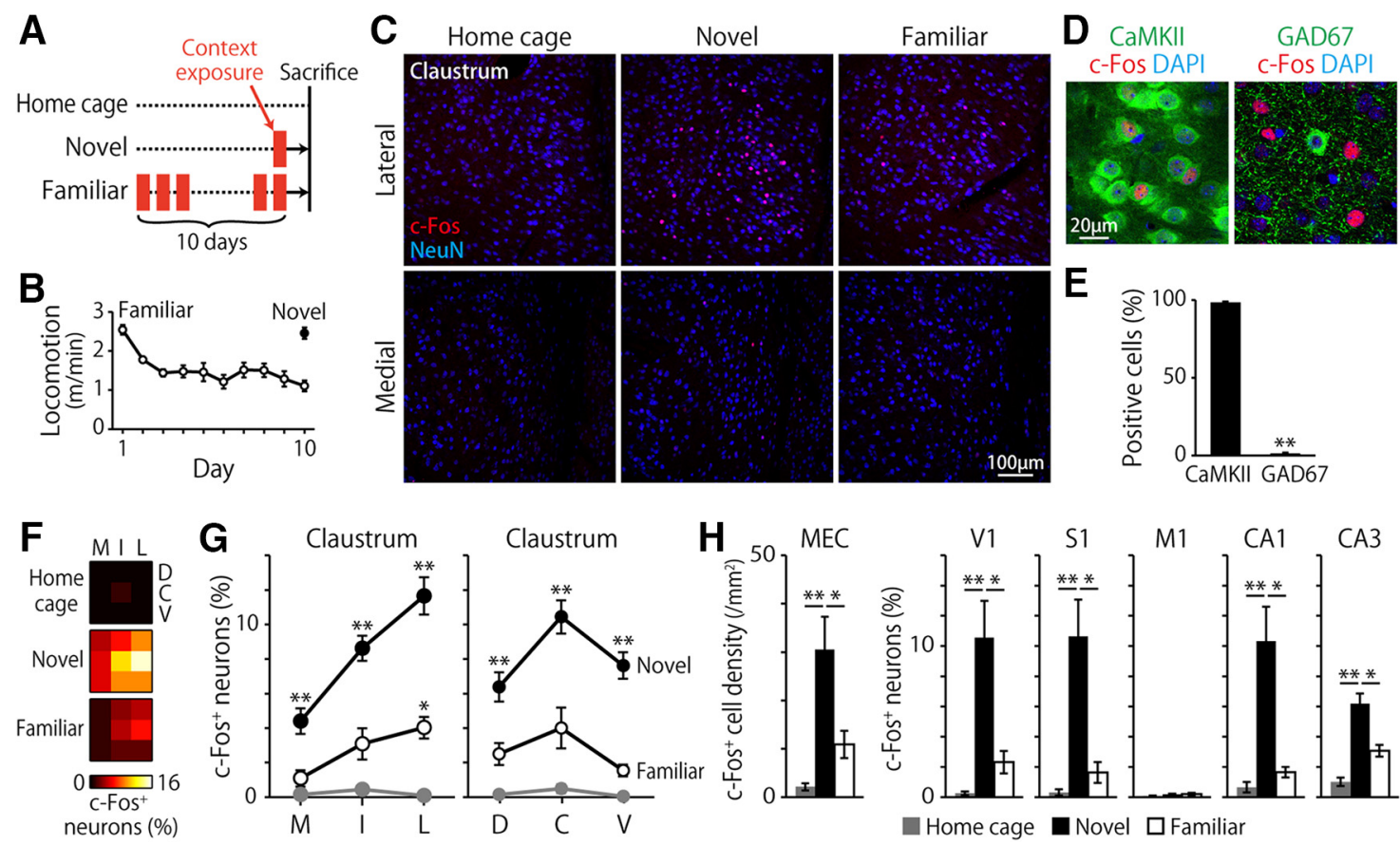

Figure 6. Novel context exposure induces c-Fos expression in the claustrum. $A$, Schematic of the environmental exposure. Mice were exposed to a chamber once (novel group) or 10 times daily (familiar group) and then killed $90 \mathrm{~min}$ after the final exposure. Mice in the home cage group were killed without any environmental exposure. $\boldsymbol{B}$, Locomotor activity of mice in the familiar ( $n=5$ mice) and novel ( $n=7$ mice) group in the chamber. C, Representative images showing the expression of c-Fos in the lateral (top) and medial (bottom) claustrum of mice from home cage (left), novel (middle), and familiar (right) groups. D, Confocal image of the claustrum of mice in the novel group showing that most c-Fos ${ }^{+}$cells express CaMKIll $\alpha$ (left) but not GAD67 (right). $\boldsymbol{E}$, Percentage of CaMKII $\alpha{ }^{+}$or GAD67 ${ }^{+}$cells within the c-Fos ${ }^{+}$cells in the claustrum. ${ }^{* *} p<0.01, t_{(12)}=124.8$, two-tailed unpaired $t$ test. $n=7$ mice. $F$, Mean percentage of c-Fos ${ }^{+}$neurons in each segment of the claustrum. The columns and rows of each matrix correspond to the mediolateral and dorsoventral locations within the claustrum, respectively (novel: $n=7$, familiar: $n=5$, home cage: $n=$ 5 mice). $F, G, M, I, L, D, C$, and V indicate the medial, intermediate, lateral, dorsal, central, and ventral segment of the claustrum, respectively. G, Percentage of c-Fos ${ }^{+}$neurons in each mediolateral (left) and dorsoventral (right) segment of the claustrum. The cells along the dorsoventral (left) and mediolateral (right) axes were pooled in this analysis. ${ }^{*} p<0.05,{ }^{* *} p<0.01$, comparison versus home cage group, post hoc Bonferroni test after two-way repeated-measures ANOVA (novel: $n=7$, familiar: $n=5$, home cage: $n=5$ mice). $\boldsymbol{H}$, Density (for MEC) or percentage (for other areas) of c-Fos ${ }^{+}$neurons. ${ }^{*} p<0.05,{ }^{* *} p<0.01$, Tukey test after one-way ANOVA (novel: $n=7$, familiar: $n=5$, home cage: $n=5$ mice).

behavioral group and the mediolateral and dorsoventral locations of the cells in the claustrum (Fig. $6 F ; p<0.001$, for all main effects, $p<0.01$, group $\times$ mediolateral interaction, 3-way ANOVA). In the novel group, c-Fos expression was elevated in all mediolateral and dorsoventral levels of the claustrum compared with that in the home-caged controls (Fig. $6 G$ ). In the familiar group, c-Fos expression was elevated in the lateral claustrum, but was significantly less than c-Fos expression in the novel group in all mediolateral and dorsoventral locations (Fig. $6 G ; p<0.01$, post hoc Bonferroni test). This between-group difference in c-Fos induction was unlikely due to the difference in locomotor activity because an analysis of covariance that included locomotion and the other factors (group, mediolateral location, and dorsoventral location) revealed that locomotion did not account significantly 
A

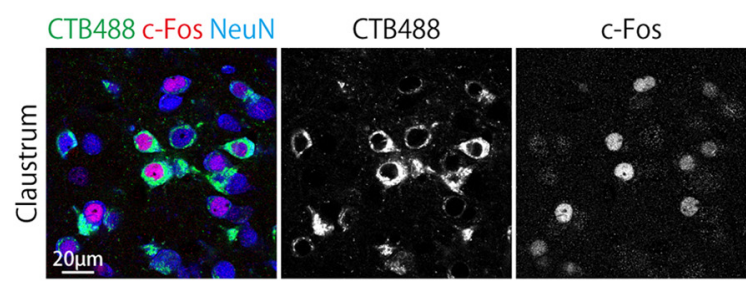

B

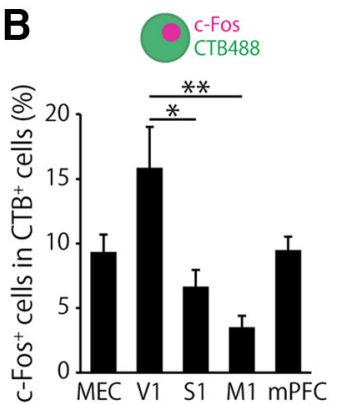

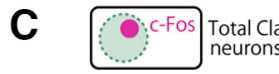

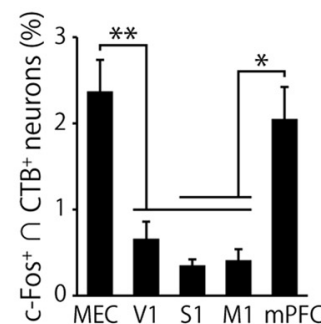

Figure 7. Activation of claustro-cortical pathways by novel context exposure. $A$, Representative confocal image showing (TB488 and c-Fos double-positive cells in the claustrum of mice exposed to a novel environment. CTB488 was injected in the MEC in this mouse. $B$, Percentage of $\mathrm{c}-\mathrm{Fos}{ }^{+}$cells within the CTB488 $^{+}$cells. (TB488 was injected into the indicated cortical area. $F_{(4,25)}=5.9$, $p<0.01$, one-way ANOVA; ${ }^{*} p<0.05,{ }^{* *} p<0.01$, Tukey test, $n=10$ (MEC) and 5 (other areas, per area). C, Percentage of c-Fos and CTB488 double-positive cells within the total claustral neuron population. $F_{(4,25)}=9.6, p<0.001$, one-way ANOVA; ${ }^{*} p<0.05$, ${ }^{* *} p<0.01$, Tukey test.

for the variance in the c-Fos expression $\left(F_{(1,89)}=3.76, p>0.05\right)$. Within the novel group, the proportion of c-Fos-expressing cells was highest in the lateral and central claustrum, as measured along both the mediolateral and dorsoventral axes (Fig. 6G; $p<0.001$, post hoc Bonferroni test). These results suggest that the claustrum is activated by the exposure to a novel environment. We also examined c-Fos expression in cortical areas connected with the claustrum and the hippocampus. The novel group showed elevated c-Fos expression compared with the homecaged or the familiar group in the following areas: MEC, V1, S1, CA1, and CA3 (Fig. 6H). In M1, c-Fos expression was unchanged by environmental exposure (Fig. $6 H ; F_{(2,14)}=1.6, p>0.1$, oneway ANOVA).

To determine the level of c-Fos expression for each population of claustro-cortical neurons projecting to a specific cortical area, mice received CTB488 injection into one of the five cortical areas (MEC, V1, S1, M1, or mPFC) before exposure to a novel chamber. Mice were exposed to the chamber for $6 \mathrm{~min}$ and then killed 90 min later for the imaging analysis (Fig. 7A). We first examined the proportion of c-Fos-positive cells within CTB488-labeled claustral neurons to estimate to what extent each pathway was activated. The proportion of c-Fos-positive cells was larger in the V1-projecting claustral neurons than in the S1-projecting or M1projecting neurons (Fig. $7 B$ ). Because the numbers of CTB488positive cells differ depending on the projection target (Fig. 2), we next estimated the proportion of c-Fos-positive cells of each claustro-cortical population among all claustral neurons (Fig. $7 C)$. This proportion was higher for the MEC than $\mathrm{V} 1, \mathrm{~S} 1$, and M1. Similarly, the proportion was higher for the mPFC than S1 and M1. These results suggest that claustro-cortical projection neurons are activated by the exposure to novel environments to varying degrees depending on the projection target and the largest proportion of the activated neurons projects to the MEC and/or mPFC.

\section{Involvement of MEC-projecting claustral neurons in contextual fear memory}

By using an AAV double infection approach, we investigated optogenetically the behavioral role of MEC-projecting claustral neurons. The MEC has been implicated in contextual fear learning (Maren and Fanselow, 1997; Majchrzak et al., 2006). Therefore, we subjected mice to three behavioral tests: an open-field test to examine general locomotor activity, an elevated plus maze to test anxiety-related behavior, and a contextual fearconditioning test.
We first bilaterally expressed slow ChloC (Wietek et al., 2014) in MEC-projecting claustral neurons by injecting a Credependent vector expressing slow ChloC after recombination (AAV1/2-EF1 $\alpha$-DIO-slow ChloC-2A-EYFP) into the lateral claustrum and the AAV6-Cre vector into the dorsal MEC (Fig. $8 A-E)$. The proportion of slow ChloC-positive neurons was $20.1 \pm 2.2 \%(n=12$ mice $)$ in the lateral claustrum. We also bilaterally implanted optical fibers terminating dorsal to the lateral claustrum. Slow ChloC is a light-sensitive anion channel that silences neuronal firing transiently in response to blue light irradiation. In contextual fear conditioning, mice were conditioned with three foot shocks in a chamber and then reexposed to the same chamber 1 and $24 \mathrm{~h}$ later without foot shocks to evaluate their contextual fear memory (Fig. 8A). Blue light pulses were delivered bilaterally to all mice throughout the conditioning session. Percentage of freezing was comparable during the training session between the slow ChloC group and the controls that express only EYFP $(p>0.1$, between-groups, group $\times$ time interaction, two-way repeated-measures ANOVA), suggesting that silencing MECprojecting claustral neurons does not affect basal freezing, freezing response to foot shocks, or fear memory acquisition. Both the slow ChloC group and EYFP controls froze similarly in the $1 \mathrm{~h}$ test $\left(F_{(1,20)}=0.24, p>0.1\right.$, between groups, two-way repeated-measures ANOVA). However, mice in the slow ChloC group showed significantly less freezing than those in the EYFP controls in the $24 \mathrm{~h}$ test $\left(F_{(1,20)}=4.6, p<0.05\right.$, between groups, two-way repeated-measures ANOVA), suggesting that the activity of MEC-projecting claustral neurons during contextual learning contributes to later memory retrieval.

In the open-field and elevated plus maze tests, blue light pulses were delivered to all mice during the middle of the testing session for $3 \mathrm{~min}$ and locomotor activity and the percentage of open arm entries were measured, respectively (Fig. $8 B, C)$. Both parameters were unchanged during blue light irradiation (Fig. $8 B, C$; $p>0.1$, group $\times$ time bin, two-way repeated-measures ANOVA). To validate neuronal silencing, mice were reexposed to the conditioned chamber for $3 \mathrm{~min}$ with blue light pulses before being killed (Fig. 8D). Claustral neurons expressing only EYFP (controls) showed robust c-Fos expression, whereas slow ChloC-expressing neurons showed less c-Fos expression (Fig. 8E), confirming successful silencing of MEC-projecting claustral neurons. 


\section{Silencing with slow ChloC}
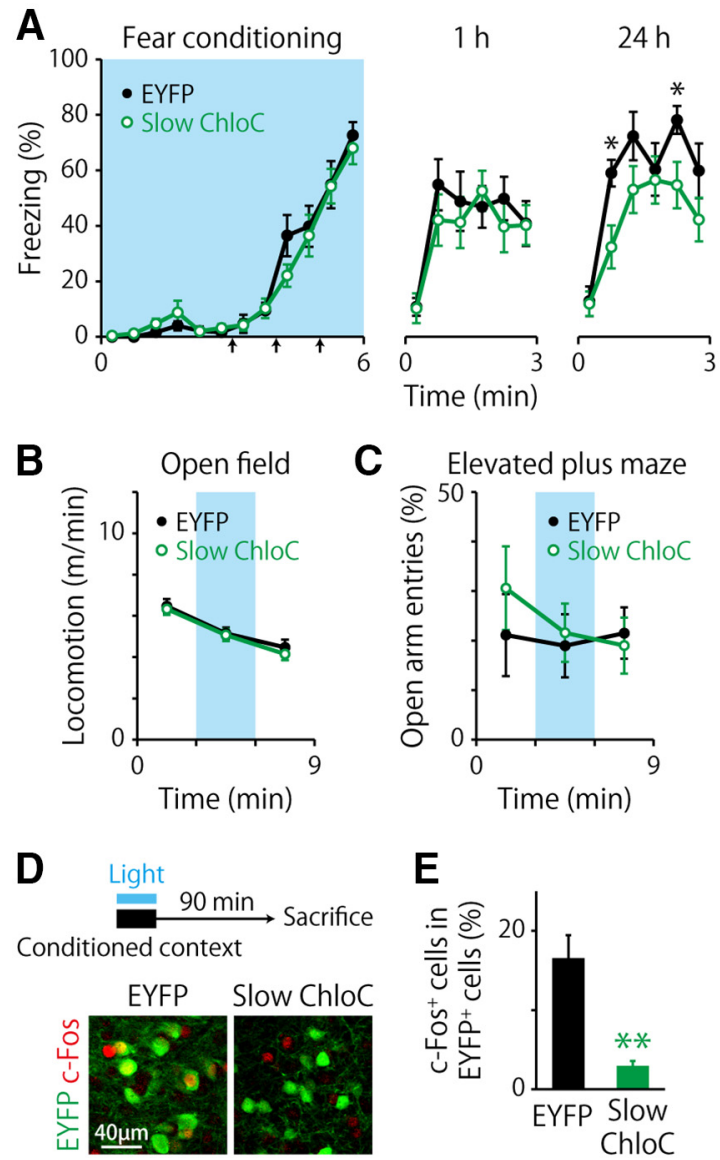
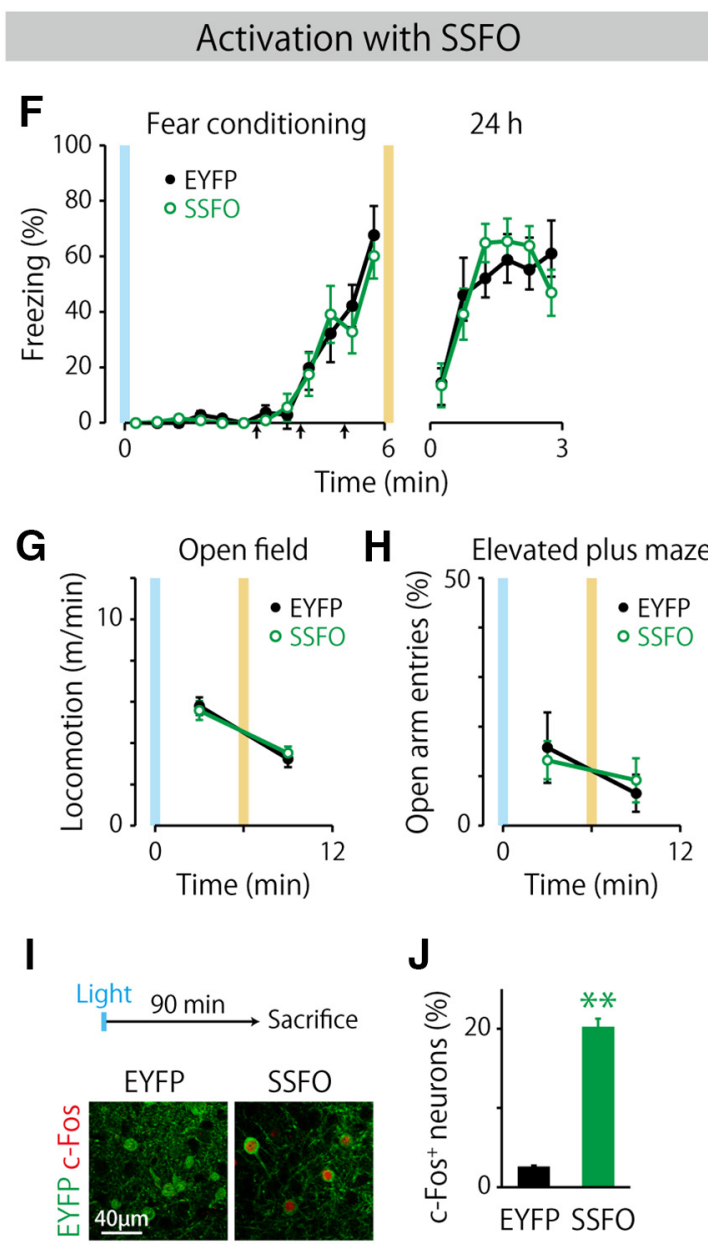

Figure 8. Behavioral role of MEC-projecting claustral neurons. $A$, Percentage of time spent freezing during contextual fear conditioning in a novel chamber and during the retrieval test in the same chamber $1 \mathrm{~h}$ and/or $24 \mathrm{~h}$ later. Blue light ( $473 \mathrm{~nm}$ ) was bilaterally delivered ( $20 \mathrm{~ms}, 1 \mathrm{~Hz}$ ) to the MEC-projecting claustral neurons expressing slow ChloC. Arrows indicate the timing of foot shocks $(0.4 \mathrm{~mA}, 2 \mathrm{~s}) .{ }^{*} p<0.05$, post hoc Bonferroni test (EYFP: $n=10$ mice, slow ChloC: $n=12$ mice). $\boldsymbol{B}$, Locomotor activity in a novel open field. Blue light pulses were given between 3 and 6 min (EYFP: $n=11$ mice, slow ChloC: $n=12$ mice). C, Percentages of open arm entries in an elevated plus maze. Blue light pulses were given between 3 and 6 min (EYFP: $n=11$ mice, slow ChloC: $n=12$ mice). $\boldsymbol{D}$, Blue light pulses were administered during the reexposure of mice to the conditioned chamber (top). Representative c-Fos staining in the claustrum of mice from the EYFP control (bottom left) and the slow ChloC group (bottom right). $\boldsymbol{E}$, Percentage of c-Fos ${ }^{+}$cells within the EYFP ${ }^{+}$claustral cells $\left({ }^{* *} p<0.01, t_{(20)}=5.0\right.$, two-tailed unpaired $t$ test; EYFP: $n=10$, slow ChloC: $\left.n=12\right)$. $\boldsymbol{F}$, Mice were bilaterally administered a blue light pulse for 5 simmediately before placement into the chamber for conditioning and a yellow light pulse for 10 s after being taken out from the chamber ( $n=8$ mice per group). Blue and yellow shaded areas indicate the timing of light administration. $\mathbf{G}$, Locomotor activity in a novel open field. A blue light pulse was given immediately before placement into the open field and a yellow light pulse was given at $6 \mathrm{~min}(n=8$ mice per group). $\boldsymbol{H}$, Percentages of open arm entries in an elevated plus maze. $\boldsymbol{I}$, Blue light pulse was administered without environmental exposure. Representative c-Fos staining in the claustrum of mice from the EYFP control (bottom left) and the SSF0 group (bottom right). $J$, Percentage of c-Fos ${ }^{+}$cells within claustral neurons ( ${ }^{* *} p<0.01, t_{(10)}=6.8$, two-tailed unpaired $t$ test; $n=6$ per group).

We next bilaterally expressed SSFO (Yizhar et al., 2011) in the MEC-projecting claustral neurons as described above using an AAV1/2-EF1 $\alpha$-DIO-SSFO-EYFP vector (Fig. $8 F-J$ ). SSFO depolarizes neurons continuously once activated with a blue light pulse and is deactivated with a yellow light pulse. During the contextual fear conditioning, mice were bilaterally administered a blue light pulse immediately before being placed into a conditioning chamber and a yellow light pulse after conditioning (Fig. $8 F$ ). Mice in the SSFO group and the EYFP controls showed comparable levels of freezing in the 24 h test $(p>0.1$, between-groups, group $\times$ time interaction, two-way repeated-measures ANOVA). In the open-field test and elevated plus maze test, a blue light pulse was delivered to all mice immediately before testing and a yellow pulse was given at the middle of the testing session (Fig. $8 G, H$ ). Both locomotion and the percentage of open arm entries were unaffected by a blue light pulse $(p>0.1$, group $\times$ time bin, two-way repeated-measures ANOVA). To confirm neuronal activation, mice were administered a blue light pulse before being killed (Fig. 8I). Proportion of c-Fos-positive cells in the claustrum was larger in the SSFO group than in the EYFP control group (Fig. 8J).

\section{Discussion}

The present study investigated the function of identified claustro-cortical pathways in mice. The major findings are as follows. The anterior part of the claustrum densely projects to the MEC and mPFC. Exposure to a novel environment induced c-Fos expression in substantial numbers of MEC- and mPFCprojecting claustral neurons and in modest numbers of V1/S1/ M1-projecting claustral neurons. MEC-projecting claustral neurons are largely separated from those projecting to primary sensory/motor cortices. MEC-projecting claustral neurons contribute to contextual fear memory. These results suggest that a previously unanticipated massive claustrum-to-MEC pathway largely separated from other claustro-cortical pathways is acti- 
vated by novel context exposure and modulates the MEC function in contextual fear memory.

\section{Anatomical organization of claustro-cortical projections}

The connectivity between the claustrum and neocortex has been investigated in various mammals such as rats, cats, monkeys, and humans (Smythies et al., 2013). Claustro-cortical projections in these species are organized such that topographically localized claustral neurons along the anteroposterior and dorsoventral axes project as a whole claustrum to almost all neocortical areas (Narkiewicz, 1964; Norita, 1977; Pearson et al., 1982; Minciacchi et al., 1985; Sloniewski et al., 1986; Morys et al., 1993; Reser et al., 2014). Despite the accumulating literature, studies in mice have been scarce (Zingg et al., 2014; Wang et al., 2016). Using retrograde and anterograde tracing, the present study showed that the claustrum in mice projects to all examined cortical areas such as the primary (V1, S1, and M1) and higher-order cortices (MEC and $\mathrm{mPFC}$ ). We also demonstrated that the claustro-cortical projections in mice are organized topographically along the mediolateral and dorsoventral axes of the claustrum. These observations indicate that, in terms of the widespread and topographic efferents, the organization of claustro-cortical projections is similar between mice and other mammals.

In broad dorsoventral parts of the anterior claustrum, the neurons originating these projections were widely distributed, but the projections to the MEC and MPFC were denser than those to primary sensory/motor cortices. However, care must be taken because retrograde labeling can be affected by a number of factors (e.g., the size of the cortical region being injected, heterogeneity within a cortical region, cortical layers in which the tracer was distributed, and neuronal efficiency of tracer take up). Although the strong projection to the $\mathrm{mPFC}$ is consistent with the results of previous tracing studies in monkeys (Reser et al., 2014), rats (Condé et al., 1995; Hoover and Vertes, 2007), and mice (Zingg et al., 2014; Wang et al., 2016), the massive projection from the claustrum to the MEC was unanticipated. In cats, both anterograde and retrograde tracings show that the dorsal claustrum projects only modestly to the MEC (Markowitsch et al., 1984; Room and Groenewegen, 1986; Witter et al., 1988). In rats, one study describes that anterograde tracing from anterior claustrum resulted in no labeled fibers in the MEC (Zhang et al., 2001), whereas a set of retrograde and anterograde tracer studies have emphasized reciprocal connections between the claustrum and MEC (Agster et al., 2016; Tomás Pereira et al., 2016). In mice, one study has described the claustro-MEC pathway (Wang et al., 2016), whereas another study has reported that the claustrum lacked a projection to the MEC (Zingg et al., 2014). The reasons of such discrepancies are unclear. CTB and AAV, which we used as tracers, might be suited to efficiently labeling the long-range claustro-MEC projection. Another reason might be that, in most of these studies, coronal sections were used, which are prone to underestimate projections to large portions of MEC. Sagittal or horizontal sections as used in this study provide a better means to assess MEC labeling. Interestingly, recent whole-brain diffusion imaging in a primate brain suggested that the claustrum has the strongest connections with the entorhinal cortex (Park et al., 2012). Therefore, the dense claustro-MEC connection in mice may be conserved in other mammalian species. Intracortical injections of CTB488 and CTB594 suggested that MEC-projecting claustral neurons form their own population largely separated from neurons projecting to other cortical areas (Fig. 3). A similar separation also applies in many other cortical areas. Injections of two retrograde tracers into various combinations of cortical areas generally result in either no or scarce double labeling in the claustrum (Macchi et al., 1983; Norita, 1983; Minciacchi et al., 1985; Sloniewski et al., 1986; Majak et al., 2000), with some exceptions (Smith et al., 2012). These results, together with the gross topographic bias in the locations of claustro-cortical neurons, suggest that the claustral projection neurons consist of largely nonoverlapping populations targeting restricted areas of neocortex.

\section{Experience-dependent activation of claustro-cortical pathways}

Exposure to a novel environment induced c-Fos expression in the claustrum. The observation of less c-Fos expression in familiar environment suggests that the c-Fos expression is not driven solely by sensory inputs. In addition, c-Fos expression did not seem to be tightly associated with the motor functions that were measured with locomotor activity. Rather, the claustrum may respond to contextual changes that are important for animals. Selective c-Fos expression in response to a novel context was also observed in the V1, S1, MEC, and hippocampus. Therefore, these c-Fos-positive cells in the claustrum and cortical areas may represent the information that is associated with contextual novelty, but it is unclear where and how such information is generated in the network. Claustral neurons fire transiently in response to salient audiovisual stimuli (Remedios et al., 2010, 2014). In addition, spatially tuned firing patterns in the MEC are modified in novel environments (Barry et al., 2012). These novelty-associated changes in firing patterns might have affected the current c-Fos expression results.

Novel context exposure induced c-Fos expression in substantial numbers of MEC- and mPFC-projecting claustral neurons and in modest numbers of V1/S1/M1-projecting claustral neurons. This pattern of c-Fos expression suggests that a particular behavior can recruit multiple claustro-cortical pathways, whereas selected pathways are predominantly activated by the behavior. Correlated sensory inputs from several cortical areas have been proposed to activate multiple claustro-cortical pathways (Smythies et al., 2012; Kim et al., 2016). Such correlated inputs might have induced the c-Fos expression that spanned multiple pathways. Conversely, rare excitatory synaptic connections between cortically projecting claustral neurons (Kim et al., 2016) may ensure that individual claustro-cortical pathways operate distinctly depending on behavioral demands, which may be reflected in the distinct proportion of c-Fos expression.

\section{Function of the claustro-MEC pathway}

The finding that the largest proportion of c-Fos-expressing cells projected to the MEC or mPFC suggests that the claustrum has a role of transmitting salient contextual information to these cortical areas. Consistently with this, recent extracellular recording in behaving rats showed that the anterior claustrum contains neurons that fire in response to place, boundary, or objects, indicating that a fraction of claustral neurons signals spatial information of the current environment (Jankowski and O'Mara, 2015). Determining whether these spatially tuned neurons project to the MEC in future research is intriguing considering that the entorhinal cortex and interconnected hippocampus also contain spatially tuned neurons (O'Keefe and Dostrovsky, 1971; Hafting et al., 2005; Deshmukh and Knierim, 2011).

The entorhinal cortex is essential for spatial and contextual memory (Hebert and Dash, 2002; Steffenach et al., 2005; Takehara-Nishiuchi, 2014). Bilateral lesions of the entorhinal cortex impair contextual fear conditioning (Maren and Fanselow, 1997; Majchrzak et al., 2006). Therefore, the involvement 
of MEC-projecting claustral neurons in contextual fear memory, but not in general locomotor activity or anxiety-related behavior, suggests that these claustral neurons affect the entorhinal cortex selectively without altering broad cortical activity. When the claustro-MEC pathway was silenced during fear conditioning, freezing behavior was left intact in the conditioning session and in the $1 \mathrm{~h}$ test, but was suppressed in the $24 \mathrm{~h}$ test. These results suggest that the activity of the claustro-MEC pathway during learning contributes to the memory processes that are important for long-term $(24 \mathrm{~h})$ memory and less important for short-term $(1 \mathrm{~h})$ memory. One such memory process is consolidation (Dudai, 2004). Although MEC layer 2/3 neurons project to the hippocampus, MEC layer 5 neurons relay hippocampal outputs to various cortical areas (Canto et al., 2008; Sürmeli et al., 2015). This hippocampal-cortical pathway mediated through the entorhinal cortex is thought to be crucial for the consolidation of hippocampus-dependent memory (Alvarez and Squire, 1994; Frankland and Bontempi, 2005; Takehara-Nishiuchi, 2014). The dense innervation of claustro-MEC neurons onto MEC layers $5 / 6$ that was observed may affect selectively the neurons having a soma in these layers. Tetanic stimulation of the claustrum enhances long-term responses for $>1 \mathrm{~h}$ in the entorhinal cortex (Wilhite et al., 1986). If such plasticity occurs during learning, then the information processing that is essential for memory consolidation might be modulated in the entorhinal cortex over a long period after learning. We therefore propose that claustroMEC activity during learning has a lasting impact on the information flow from the hippocampus to cerebral cortex mediated by the deep layer of the MEC, thereby contributing to properly completing the consolidation of contextual fear memories. Further pathway-specific research is needed to reveal fully the function of the claustrum.

\section{References}

Agster KL, Tomás Pereira I, Saddoris MP, Burwell RD (2016) Subcortical connections of the perirhinal, postrhinal, and entorhinal cortices of the rat. II. Efferents. Hippocampus 26:1213-1230. CrossRef Medline

Alvarez P, Squire LR (1994) Memory consolidation and the medial temporal lobe: a simple network model. Proc Natl Acad Sci U S A 91:7041-7045. CrossRef Medline

Arimatsu Y, Miyamoto M, Nihonmatsu I, Hirata K, Uratani Y, Hatanaka Y, Takiguchi-Hayashi K (1992) Early regional specification for a molecular neuronal phenotype in the rat neocortex. Proc Natl Acad Sci U S A 89: 8879-8883. CrossRef Medline

Aronoff R, Matyas F, Mateo C, Ciron C, Schneider B, Petersen CC (2010) Long-range connectivity of mouse primary somatosensory barrel cortex. Eur J Neurosci 31:2221-2233. CrossRef Medline

Barry C, Ginzberg LL, O'Keefe J, Burgess N (2012) Grid cell firing patterns signal environmental novelty by expansion. Proc Natl Acad Sci U S A 109:17687-17692. CrossRef Medline

Brand S (1981) A serial section Golgi analysis of the primate claustrum. Anat Embryol (Berl) 162:475-488. CrossRef Medline

Byun J, Verardo MR, Sumengen B, Lewis GP, Manjunath BS, Fisher SK (2006) Automated tool for the detection of cell nuclei in digital microscopic images: application to retinal images. Mol Vis 12:949-960. Medline

Canto CB, Wouterlood FG, Witter MP (2008) What does the anatomical organization of the entorhinal cortex tell us? Neural Plast 2008:381243. CrossRef Medline

Chau A, Salazar AM, Krueger F, Cristofori I, Grafman J (2015) The effect of claustrum lesions on human consciousness and recovery of function. Conscious Cogn 36:256-264. CrossRef Medline

Clarey JC, Irvine DR (1986) Auditory response properties of neurons in the claustrum and putamen of the cat. Exp Brain Res 61:432-437. Medline

Condé F, Maire-Lepoivre E, Audinat E, Crépel F (1995) Afferent connections of the medial frontal cortex of the rat. II. Cortical and subcortical afferents. J Comp Neurol 352:567-593. CrossRef Medline

Crick FC, Koch C (2005) What is the function of the claustrum? Philos Trans R Soc Lond B Biol Sci 360:1271-1279. CrossRef Medline
Deshmukh SS, Knierim JJ (2011) Representation of non-spatial and spatial information in the lateral entorhinal cortex. Front Behav Neurosci 5:69. CrossRef Medline

Dudai Y (2004) The neurobiology of consolidations, or, how stable is the engram? Annu Rev Psychol 55:51-86. CrossRef Medline

Edelstein LR, Denaro FJ (2004) The claustrum: a historical review of its anatomy, physiology, cytochemistry and functional significance. Cell Mol Biol (Noisy-le-grand) 50:675-702. Medline

Frankland PW, Bontempi B (2005) The organization of recent and remote memories. Nat Rev Neurosci 6:119-130. Medline

Franklin KBJ, Paxinos G (2008) The mouse brain in stereotaxic coordinates, Ed 3. Amsterdam/New York: Elsevier/Academic.

Hafting T, Fyhn M, Molden S, Moser MB, Moser EI (2005) Microstructure of a spatial map in the entorhinal cortex. Nature 436:801-806. CrossRef Medline

Hebert AE, Dash PK (2002) Extracellular signal-regulated kinase activity in the entorhinal cortex is necessary for long-term spatial memory. Learn Mem 9:156-166. CrossRef Medline

Hoover WB, Vertes RP (2007) Anatomical analysis of afferent projections to the medial prefrontal cortex in the rat. Brain Struct Funct 212:149-179. CrossRef Medline

Jankowski MM, O’Mara SM (2015) Dynamics of place, boundary and object encoding in rat anterior claustrum. Front Behav Neurosci 9:250. CrossRef Medline

Kim J, Matney CJ, Roth RH, Brown SP (2016) Synaptic organization of the neuronal circuits of the claustrum. J Neurosci 36:773-784. CrossRef Medline

Kitanishi T, Ujita S, Fallahnezhad M, Kitanishi N, Ikegaya Y, Tashiro A (2015) Novelty-induced phase-locked firing to slow gamma oscillations in the hippocampus: requirement of synaptic plasticity. Neuron 86:12651276. CrossRef Medline

Koubeissi MZ, Bartolomei F, Beltagy A, Picard F (2014) Electrical stimulation of a small brain area reversibly disrupts consciousness. Epilepsy Behav 37:32-35. CrossRef Medline

Lavenex P, Amaral DG (2000) Hippocampal-neocortical interaction: a hierarchy of associativity. Hippocampus 10:420-430. Medline

LeVay S, Sherk H (1981) The visual claustrum of the cat. I. Structure and connections. J Neurosci 1:956-980. Medline

Macchi G, Bentivoglio M, Minciacchi D, Molinari M (1983) Claustroneocortical projections studied in the cat by means of multiple retrograde fluorescent tracing. J Comp Neurol 215:121-134. CrossRef Medline

Majak K, Kowiánski P, Morýs J, Spodnik J, Karwacki Z, Wisniewski HM (2000) The limbic zone of the rabbit and rat claustrum: a study of the claustrocingulate connections based on the retrograde axonal transport of fluorescent tracers. Anat Embryol 201:15-25. CrossRef Medline

Majchrzak M, Ferry B, Marchand AR, Herbeaux K, Seillier A, Barbelivien A (2006) Entorhinal cortex lesions disrupt fear conditioning to background context but spare fear conditioning to a tone in the rat. Hippocampus 16:114-124. CrossRef Medline

Maren S, Fanselow MS (1997) Electrolytic lesions of the fimbria/fornix, dorsal hippocampus, or entorhinal cortex produce anterograde deficits in contextual fear conditioning in rats. Neurobiol Learn Mem 67:142-149. CrossRef Medline

Markowitsch HJ, Irle E, Bang-Olsen R, Flindt-Egebak P (1984) Claustral efferents to the cat's limbic cortex studied with retrograde and anterograde tracing techniques. Neuroscience 12:409-425. CrossRef Medline

Matsuo N (2015) Irreplaceability of neuronal ensembles after memory allocation. Cell Rep 11:351-357. CrossRef Medline

Minciacchi D, Molinari M, Bentivoglio M, Macchi G (1985) The organization of the ipsi- and contralateral claustrocortical system in rat with notes on the bilateral claustrocortical projections in cat. Neuroscience 16:557576. CrossRef Medline

Morgan JI, Cohen DR, Hempstead JL, Curran T (1987) Mapping patterns of c-fos expression in the central nervous system after seizure. Science 237: 192-197. CrossRef Medline

Morys J, Narkiewicz O, Wisniewski HM (1993) Neuronal loss in the human claustrum following ulegyria. Brain Res 616:176-180. CrossRef Medline

Narkiewicz O (1964) Degenerations in the claustrum after regional neocortical ablations in the cat. J Comp Neurol 123:335-355. CrossRef Medline

Norita M (1977) Demonstration of bilateral claustro-cortical connections in the cat with the method of retrograde axonal transport of horseradish peroxidase. Arch Histol Jpn 40:1-10. Medline 
Norita M (1983) Claustral neurons projecting to the visual cortical areas in the cat: a retrograde double-labeling study. Neurosci Lett 36:33-36. CrossRef Medline

O'Keefe J, Dostrovsky J (1971) The hippocampus as a spatial map: preliminary evidence from unit activity in the freely-moving rat. Brain Res 34: 171-175. Medline

Olson CR, Graybiel AM (1980) Sensory maps in the claustrum of the cat. Nature 288:479-481. CrossRef Medline

Park S, Tyszka JM, Allman JM (2012) The claustrum and insula in Microcebus murinus: a high resolution diffusion imaging study. Front Neuroanat 6:21. CrossRef Medline

Pearson RC, Brodal P, Gatter KC, Powell TP (1982) The organization of the connections between the cortex and the claustrum in the monkey. Brain Res 234:435-441. CrossRef Medline

Rabinowitz JE, Rolling F, Li C, Conrath H, Xiao W, Xiao X, Samulski RJ (2002) Cross-packaging of a single adeno-associated virus (AAV) type 2 vector genome into multiple AAV serotypes enables transduction with broad specificity. J Virol 76:791-801. CrossRef Medline

Remedios R, Logothetis NK, Kayser C (2010) Unimodal responses prevail within the multisensory claustrum. J Neurosci 30:12902-12907. CrossRef Medline

Remedios R, Logothetis NK, Kayser C (2014) A role of the claustrum in auditory scene analysis by reflecting sensory change. Front Syst Neurosci 8:44. CrossRef Medline

Reser DH, Richardson KE, Montibeller MO, Zhao S, Chan JM, Soares JG, Chaplin TA, Gattass R, Rosa MG (2014) Claustrum projections to prefrontal cortex in the capuchin monkey (Cebus apella). Front Syst Neurosci 8:123. CrossRef Medline

Room P, Groenewegen HJ (1986) Connections of the parahippocampal cortex in the cat. 2. Subcortical afferents. J Comp Neurol 251:451-473. CrossRef Medline

Segundo JP, Machne X (1956) Unitary responses to afferent volleys in lenticular nucleus and claustrum. J Neurophysiol 19:325-339. Medline

Sherk H, LeVay S (1981) Visual claustrum: topography and receptive field properties in the cat. Science 212:87-89. CrossRef Medline

Sloniewski P, Usunoff KG, Pilgrim C (1986) Retrograde transport of fluorescent tracers reveals extensive ipsi- and contralateral claustrocortical connections in the rat. J Comp Neurol 246:467-477. CrossRef Medline

Smith JB, Radhakrishnan H, Alloway KD (2012) Rat claustrum coordinates but does not integrate somatosensory and motor cortical information. J Neurosci 32:8583-8588. CrossRef Medline

Smythies J, Edelstein L, Ramachandran V (2012) Hypotheses relating to the function of the claustrum. Front Integr Neurosci 6:53. CrossRef Medline
Smythies J, Edelstein L, Ramachandran VS (2013) The claustrum: structural, functional, and clinical neuroscience. San Diego: Academic.

Spector I, Hassmann.J, Albefess D (1974) Sensory properties of single neurons of cats claustrum. Brain Res 66:39-65. CrossRef

Steffenach HA, Witter M, Moser MB, Moser EI (2005) Spatial memory in the rat requires the dorsolateral band of the entorhinal cortex. Neuron 45:301-313. CrossRef Medline

Sürmeli G, Marcu DC, McClure C, Garden DL, Pastoll H, Nolan MF (2015) Molecularly defined circuitry reveals input-output segregation in deep layers of the medial entorhinal cortex. Neuron 88:1040-1053. CrossRef Medline

Takehara-Nishiuchi K (2014) Entorhinal cortex and consolidated memory. Neurosci Res 84:27-33. CrossRef Medline

Tomás Pereira IT, Agster KL, Burwell RD (2016) Subcortical connections of the perirhinal, postrhinal, and entorhinal cortices of the rat. I. Afferents. Hippocampus 26:1189-1212. CrossRef Medline

Wang Q, Ng L, Harris JA, Feng D, Li Y, Royall JJ, Oh SW, Bernard A, Sunkin SM, Koch C, Zeng H (2016) Organization of the connections between claustrum and cortex in the mouse. J Comp Neurol. Advance online publication. Retrieved May 25, 2016. doi: 10.1002/cne.24047.

Wietek J, Wiegert JS, Adeishvili N, Schneider F, Watanabe H, Tsunoda SP, Vogt A, Elstner M, Oertner TG, Hegemann P (2014) Conversion of channelrhodopsin into a light-gated chloride channel. Science 344:409412. CrossRef Medline

Wilhite BL, Teyler TJ, Hendricks C (1986) Functional relations of the rodent claustral-entorhinal-hippocampal system. Brain Res 365:54-60. CrossRef Medline

Witter MP, Room P, Groenewegen HJ, Lohman AH (1988) Reciprocal connections of the insular and piriform claustrum with limbic cortex: an anatomical study in the cat. Neuroscience 24:519-539. CrossRef Medline

Yizhar O, Fenno LE, Prigge M, Schneider F, Davidson TJ, O’Shea DJ, Sohal VS, Goshen I, Finkelstein J, Paz JT, Stehfest K, Fudim R, Ramakrishnan C, Huguenard JR, Hegemann P, Deisseroth K (2011) Neocortical excitation/inhibition balance in information processing and social dysfunction. Nature 477:171-178. CrossRef Medline

Zhang X, Hannesson DK, Saucier DM, Wallace AE, Howland J, Corcoran ME (2001) Susceptibility to kindling and neuronal connections of the anterior claustrum. J Neurosci 21:3674-3687. Medline

Zingg B, Hintiryan H, Gou L, Song MY, Bay M, Bienkowski MS, Foster NN, Yamashita S, Bowman I, Toga AW, Dong HW (2014) Neural networks of the mouse neocortex. Cell 156:1096-1111. CrossRef Medline 